\title{
EUTOMIA
}

Revista de Literatura e Linguística

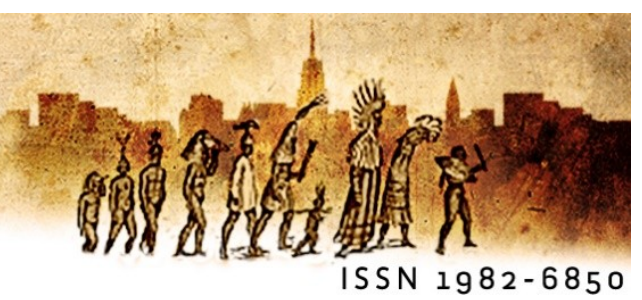

\section{Didática da escrita: reflexões sobre o desenvolvimento da capacidade de produção escrita}

\author{
Fatiha Dechicha Parahybai (UFPE)
}

\begin{abstract}
Resumo:
O artigo apresenta uma reflexão sobre o papel da escola e do ensino no desenvolvimento da capacidade linguístico-discursiva na língua inglesa do aluno universitário. Com base em uma pesquisa bibliográfica, buscamos apreender a complexidade da escrita a partir da visão vygotskiana e o que ela implica em termos de aprendizagem e de desenvolvimento. Para esse fim, discutimos o conceito de 'zona de desenvolvimento proximal' na sua concepção mais detalhada do conceito de 'desenvolvimento', mostrando a relação entre ensino e desenvolvimento, bem como as condições nas quais o indivíduo se desenvolve e transforma seu comportamento de linguagem.

Palavras-chave: escrita; ensino e aprendizagem; desenvolvimento.
\end{abstract}

\section{Résumé:}

Dans cet article, nous présentons une réflexion sur le rôle de l'école et de l'enseignement pour le développement des capacités langagières et discursives des étudiants universitaires, apprenants de l'anglais comme langue étrangère. À partir d'une recherche bibliographique, nous cherchons à appréhender la complexité de l'écriture telle qu'elle a été conçue par Vygotski et ce qu' elle implique en termes d'apprentissage et de développement. À cet effet, nous discutons le concept de 'zone de proche développement' sous une conception plus détaillée de 'développement', tout en montrant le rapport entre enseignement et développement ainsi que les conditions dans lesquelles I'individu se développe et transforme son comportement langagier.

Mots-clés: écriture; enseignement et apprentissage; développement.

\section{Introdução}

Neste artigo, nosso objetivo consiste em apresentar uma discussão acerca do papel da escola e do ensino no desenvolvimento das capacidades de linguagem de aprendizes de produção escrita na língua inglesa. Mediante uma pesquisa 
bibliográfica ${ }^{1}$, buscamos apreender a concepção de Vygotski acerca do desenvolvimento da criança (ou do adulto) e identificar os elementos que podem contribuir para o desenvolvimento da capacidade linguístico-discursiva do sujeito escritor. Para isso, discutimos a relevância do ensino focalizando os processos implicados para catalisar o desenvolvimento. Nessa discussão, apresentamos o conceito de 'zona de desenvolvimento proximal' na sua concepção mais detalhada do conceito de 'desenvolvimento', mostrando a relação entre ensino e desenvolvimento, bem como as condições nas quais o indivíduo se desenvolve e transforma seu comportamento de linguagem. Em vista disso, nosso propósito é salientar que a noção de zona de desenvolvimento proximal ou 'potencial' é essencial para se pensar em qualquer ação de formação, independentemente da idade do aprendiz.

Discutir a questão do ensino e do desenvolvimento implica falar do papel do professor no processo como um todo. Dessa maneira, abordamos os aspectos relacionados com a formação e os saberes necessários para seu trabalho. Ao mesmo tempo, apresentamos uma reflexão sobre as representações do professor em relação ao objeto de ensino e sua influência no agir do professor.

Através dessas incursões, face às dificuldades relativas à produção escrita em inglês de alunos universitários, nosso propósito é enfatizar a relevância do ensino sistemático da produção escrita na língua estrangeira com vistas ao desenvolvimento das capacidades de linguagem dos alunos.

\section{Breve olhar sobre a produção escrita em inglês no ensino superior}

As dificuldades na escrita são relatadas em diferentes pesquisas em todos os níveis de ensino, seja ele Fundamental, Médio ou Superior; seja no Brasil ou no exterior e nas línguas materna e estrangeira (Schneuwly, 2008; Dolz, et al., 2010; Assis, 2014, 2015; Pereira e Graça, 2015; Parahyba e Leurquin, 2015; Boch e Grossman, 2015). Essa constatação indica que os problemas relacionados com o ensino e aprendizagem da escrita persistem. Isso nos leva aos seguintes questionamentos: as dificuldades resultam: da ausência de ensino?; da falta de saberes?; de práticas

\footnotetext{
${ }^{1}$ Este artigo é um recorte da tese de doutorado da autora, intitulada: Avaliação e reescrita: desenvolvimento das capacidades de produção textual em inglês, Universidade Federal da Paraíba, 2011. O texto foi editado para a presente publicação.
} 
sedimentadas? Tais perguntas nos remetem à questão da formação docente, seja ela inicial ou continuada, e da maneira como o ensino e aprendizagem da escrita são tratados assim como os saberes relativos a ela.

No contexto da pesquisa de nossa autoria (PARAHYBA, 2011, p. 283), chegamos à conclusão de que "as dificuldades de produção escrita dos aprendizes adultos resultam tanto do domínio da linguagem em L2 quanto do conhecimento dos gêneros". Entre os fatores que contribuíram para esse resultado, identificamos: (a) a inexistência ou raridade de ensino sistemático na instituição pesquisada e (b) o saber lacunar dos professores sobre a escrita. Outro elemento conclusivo é nosso entendimento de que as capacidades de produção escrita são um reflexo do histórico da aprendizagem da escrita de cada aluno, inclusive na língua materna, sobretudo, se considerarmos que "o ensino de uma língua estrangeira a um aluno escolar se funda no conhecimento da língua materna como sua própria base" (VYGOTSKI, 2009, p. 267).

O trabalho evidenciou igualmente que o ensino progressivo e sistemático concorre para o desenvolvimento das capacidades linguístico-discursivas do aprendiz de língua inglesa. Dessa maneira, os resultados relatados na referida pesquisa corroboram a relevância do ensino e seus efeitos na aprendizagem do sujeito escritor, atendendo as condições de desenvolvimento preceituadas por Vygotski.

\section{Desenvolvimento na concepção de Vygotski}

Falar do papel primordial da escola e do ensino pode parecer uma obviedade. No entanto, o posicionamento segundo o qual a escola desempenha um papel fundamental no processo de desenvolvimento encontra respaldo em trabalhos de Perrenoud Aebi (1997), Bronckart (2006, 2008), Schneuwly (2008) e Friedrich (2010), todos ancorados na teoria de Vygotski. Este último salienta que "a aprendizagem é, na idade escolar, o momento decisivo e determinante de todo o destino do desenvolvimento intelectual da criança, inclusive do desenvolvimento dos seus conceitos" (VYGOTSKI, 2009, p.262). Para ele, o ensino tem um "papel decisivo" (VYGOTSKI, op.cit., p. 290) na tomada de consciência dos conceitos científicos. Ainda segundo a concepção vygotskiana, o ensino é essencial para o desenvolvimento dos 
alunos, e a função do professor é mediar o aluno na construção do saber e no desenvolvimento de suas capacidades de linguagem.

O conceito de 'zona de desenvolvimento proximal' ${ }^{2}$ de Vygotski é discutido e citado com frequência na literatura relacionada com psicologia e áreas como a sociologia, a pedagogia e a didática. Contudo, na visão de Schneuwly (2008), mesmo que esteja contido na expressão, o conceito de 'desenvolvimento' é pouco estudado. O entendimento parece se resumir ao fato de que o desenvolvimento das funções psíquicas superiores ocorre através da mediação de adultos ou de crianças mais experientes. A ênfase é dada à interação e à cooperação para que haja aprendizagem. Outra visão mostra que o ensino se torna útil quando é adaptado às capacidades da criança. Assim, "o problema do desenvolvimento se restringe à aprendizagem" (SCHNEUWLY, op. cit., p. 27$)^{3}$

Na concepção de Vygotski, "o desenvolvimento acompanha a aprendizagem e o ensino" (SCHNEUWLY, 2008, p. 14). Na interpretação de Schneuwly, há três teses no cerne dessa concepção: (a) a relação entre o sujeito e a realidade é sempre socialmente mediatizada; (b) todas as funções psíquicas superiores, entre elas o pensamento verbal e a linguagem escrita, resultam diretamente das relações sociais, das relações interpsíquicas que constituem a interiorização e (c) a interiorização ocorre sob forma de distinção de funções não diferenciadas anteriormente.

Para situar melhor o leitor em relação ao tema "desenvolvimento, ensino e capacidades humanas", apresentaremos de forma sucinta o entendimento de Vygotski sobre o objeto da psicologia. Trata-se de entender como se formam e se desenvolvem as funções psíquicas superiores (SCHNEUWLY, 2008). Friedrich (2010), na sua análise acerca da discussão sobre essa concepção, explica que, para Vygotski, o que deve ser analisado são os instrumentos ou os meios que visam a dominar e desenvolver os processos psíquicos. Isso nos conduz ao entendimento de Vygotski sobre o comportamento humano. Com base nas propostas teóricas de Marx e de

\footnotetext{
2 O conceito mais difundido é "zona de desenvolvimento proximal". A tradução de Paulo Bezerra do livro de Vygotski (2009), feita diretamente do russo, sugere "zona de desenvolvimento imediato" com base no uso e entendimento da metáfora do amadurecimento das macieiras. A acepção da palavra 'imediato', ao nosso ver, dá a entender que a ação tem que acontecer logo, não sendo uma ação iminente, próxima de acontecer. Na opinião de Schneuwly (2008), a melhor e mais precisa definição do termo foi dada pela tradutora do livro Pensamento e Linguagem", Françoise Sève. O conceito que utiliza é "zone de proche développement", ou seja, 'de desenvolvimento próximo'.

${ }^{3}$ Todas as citações das obras citadas em língua estrangeira foram traduzidas pela autora.
} 
Engels, o autor russo compreende que a ação do homem sobre a natureza, pelo fato de nunca ser imediata, é mediatizada por objetos socialmente elaborados. Tais objetos resultam de experiências de gerações anteriores e através deles as possíveis experiências são ampliadas e transmitidas. Esses objetos - as ferramentas -, que se encontram entre $\mathrm{o}$ homem e a natureza, determinam e transformam seu comportamento (SCHNEUWLY, op.cit.). O que se depreende da concepção Vygotskiana pode ser resumido da seguinte forma: a sociedade deve ser considerada como o principal fator que determina o comportamento humano, e não a natureza (VYGOTSKI, 1931/1974, apud SCHNEUWLY, op. cit.). A partir dessa compreensão, Schneuwly explica que as capacidades humanas são construídas socialmente.

\section{Zona de desenvolvimento proximal}

Para discutir a concepção de Vygotski sobre a relação entre ensino e desenvolvimento, convém apresentar as três teorias sobre o tema vigentes na sua época (VYGOTSKI, 1985; SCHNEUWLY, 2008; e FRIEDRICH, 2010). A primeira considera a aprendizagem e o desenvolvimento como dois processos independentes $\mathrm{e}$ que o percurso do desenvolvimento precede o da aprendizagem. A segunda teoria vê a aprendizagem e o desenvolvimento como um processo único. Os dois processos coincidem. A terceira postula uma verdadeira interdependência entre aprendizagem e desenvolvimento.

Contrariamente ao que outras teorias defenderam, para o pesquisador russo, "o único bom ensino é aquele que precede o desenvolvimento" (VYGOTSKI, 1985). Para ele, essa fórmula traduz a teoria de zona de desenvolvimento proximal. O diferencial dessa concepção reside no fato de que é necessário considerar o desenvolvimento atual da criança (SCHNEUWLY, 2008), ou seja, o ponto de partida do ensino tem que considerar as capacidades iniciais do aprendiz (DOLZ et al., 2010). A concepção de Vygotski (op. cit.) resume-se em duas teses: (a) a característica fundamental do ensino ${ }^{4}$ consiste na formação de uma zona de desenvolvimento proximal. O ensino desperta, estimula e faz nascer na criança uma série de processos internos de desenvolvimento. Esses processos, "a um dado momento, são accessíveis

\footnotetext{
${ }^{4}$ A palavra no texto original em francês é 'apprentissage' 'aprendizagem'. Optamos por usar 'ensino' como em Schneuwly (2008). Friedrich (2010) mantém a acepção da palavra original.
}

Eutomia, Recife, 19 (1): 178-199, Jul. 2017 
a ela apenas no âmbito da comunicação com o adulto e da colaboração com seus colegas, mas que, uma vez internalizados, tornar-se-ão a conquista própria da criança" (VYGOTSKI, op. cit., p. 112); (b) "os processos de desenvolvimento não coincidem com os processos [do ensino e] da aprendizagem, mas seguem esses últimos fazendo nascer o que definimos como zona de desenvolvimento proximal" (VYGOTSKI, op. cit., p. 114).

$\mathrm{Na}$ análise da concepção de Vygotski sobre a zona de desenvolvimento proximal, Schneuwly (2008, p. 39) explica que a diferença entre essa concepção e aquela sustentada em outras pesquisas consiste no fato de que "a zona é o resultado do cruzamento entre duas lógicas ou entre duas ações humanas: o ensino e o desenvolvimento". Segundo essa lógica, pode-se pensar em uma ação 'fictícia' na qual o professor elege aquilo que poderia ser o próximo desenvolvimento e "ensina como se esse desenvolvimento fosse automaticamente se tornar o efeito de seu ensino. E é [exatamente] esse ensino que cria a zona [de desenvolvimento proximal]". Sob outro prisma, o papel do ensino não consiste em implantar "mecanicamente novas funções psíquicas na criança, mas coloca à disposição as ferramentas e cria as condições necessárias para que a criança ou o aluno possa construí-las" (SCHNEUWLY, 2008, p. 39). A figura que segue, concebida por nós, ilustra a zona de desenvolvimento proximal, ou seja, a zona do cruzamento do ensino e do desenvolvimento e a relação entre eles.

Figura 1 - ZDP, ensino e desenvolvimento

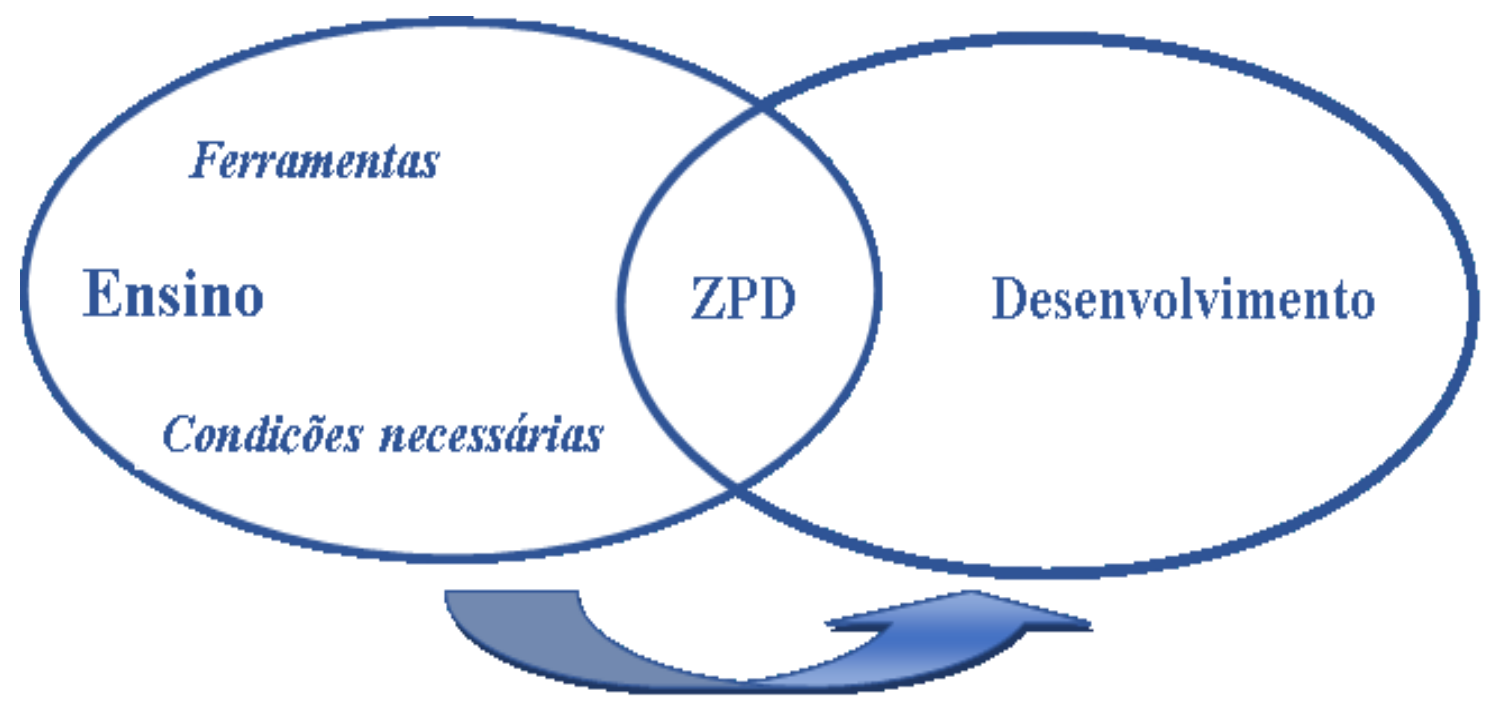

Fonte: Parahyba, 2011. 
Noutros termos, o ensino ativa o desenvolvimento. Inversamente, o desenvolvimento depende do ensino e daquilo que o professor determina como objeto de ensino visando ao desenvolvimento. Nessa perspectiva, como mostra Friedrich (2010, p. 124) o sucesso do ensino é determinado pelo "poder fazer" e pelo "saber fazer". Estes são atestados pelo desenvolvimento do indivíduo. Visto por outro ângulo, o sucesso do ensino tem como pressuposto o estabelecimento e a construção da zona de desenvolvimento proximal (SCHNEUWLY, 2008). Nesse sentido, "o conhecimento não é dado, nem adquirido, é mostrado, acentuado e demonstrado pelo professor" (FRIEDRICH, op. cit., p. 124) e com base nessas 'operações', ou seja, no ensino ao qual é confrontado, o indivíduo constrói o saber. Segundo a autora, o que o professor mostra é utilizado como 'instrumento' que se transforma.

Resumindo as concepções de ensino e desenvolvimento de Vygotski, Schneuwly (2008, p. 41) discute a razão de ser da zona de desenvolvimento proximal. A partir do problema teórico posto pelos dois postulados da teoria vygotskiana relativa ao desenvolvimento, fica evidente que: (a) o desenvolvimento das funções psíquicas superiores é concebido como "automovimento", em decorrência da reorganização e da 'revolução' das funções inferiores; (b) ao mesmo tempo, pelo fato de as funções superiores serem consideradas como construções histórico-culturais com base nos sistemas semióticos, isso implica que elas se originam apenas externamente. Sendo assim, o desenvolvimento é inteiramente dependente da educação e do ensino. Segundo o autor, através do conceito de zona de desenvolvimento proximal, Vygotski tentou articular teoricamente os dois postulados, aparentemente contraditórios. Em resumo, para Schneuwly (2008, p. 41), a zona de desenvolvimento proximal:

- nasce do ponto de encontro entre exigências externas e possibilidades internas; é precisamente a tensão que cria esse cruzamento;

- constitui o ponto de encontro entre dois tipos de processos: um relativamente sistemático, funcionando passo a passo segundo uma progressão bastante regular, abordando diferentes aspectos de um sistema em sequência um após o outro; o outro procede mais por salto pela organização súbita de elementos diversos do psiquismo, criando sistemas inteiramente novos e modificando os antigos;

- o desenvolvimento é dependente do [mundo] externo, através dos processos de ensino e de educação, de aprendizagem e de imitação, 
naquilo que esses últimos definem os conteúdos, a direção e os meios de desenvolvimento; o desenvolvimento é submissão;

- o desenvolvimento é automovimento, define seu próprio ritmo, sua própria forma de desenvolvimento, inclusive o não-ritmo, pela apropriação de elementos externos, segundo sua própria lógica; não há possível implantação de processos novos; o desenvolvimento é escolha e liberdade.

A nosso ver, o último ponto destacado por Schneuwly constitui um ponto crucial para reflexão, na medida em que nos lembra que cada indivíduo tem seu próprio ritmo de aprendizagem e de desenvolvimento. Por outro lado, Bronckart nos lembra que para Vygotski, desenvolvimento constitui "um processo ininterrupto de automovimento" (1931[1990], apud Bronckart, 2013, p.88). Dessa maneira, pelo fato de constituir um processo ininterrupto, entendemos que desenvolvimento não se restringe à idade tenra e que esse processo pode se estender a períodos de idade mais avançada quando houver ensino e formação. A partir desse entendimento, defendemos que a concepção vygotskiana de desenvolvimento pode ser igualmente aplicada à formação do adulto e ao seu potencial de desenvolvimento.

Com base no resumo que faz do esquema de desenvolvimento vygotskiano, Bronckart (Op. Cit.) acrescenta outro aspecto. Segundo ele, o desenvolvimento é condicionado à disposição da pessoa (ou do aprendiz) de querer se apropriar dos instrumentos propiciados pelo formador. O autor argumenta que:

os aportes externos são geradores de desenvolvimento apenas na medida em que conflitos que eles geram sejam "gerenciáveis' pela pessoa em seu estado atual de desenvolvimento; e nesse sentido, a identificação desta "zona" de eficácia é sempre uma "aposta", o formador propõe os elementos que lhe parecem ser exploráveis à pessoa em questão. Mas é esta última, e ela somente, que se desenvolve... ou não" (Bronckart, 2013, p.9o. Grifo nosso)

Em suma, compartilhamos com o pensamento dos autores supracitados e dos argumentos apresentados por eles, na medida em que, além do ritmo próprio de aprendizagem, cada pessoa tem interesses próprios no que diz respeito aos elementos e instrumentos a serem internalizados por ela. Tais argumentos nos alertam sobre o entendimento do conceito de "zona de desenvolvimento proximal". Não se trata apenas de mediação na sua acepção primária de 'ajuda'. Os argumentos evidenciam a relevância da escola e do ensino e, por conseguinte, do papel do 
professor, para potencializar o desenvolvimento e a transformação do agir de linguagem do aluno.

Friedrich (2010, p. 127) esclarece que "o desenvolvimento do [indivíduo] depende exclusivamente dos saberes e do conhecimento adquiridos na escola". Nesse sentido, o professor é o agente propiciador de transformação, na medida em que, "de fato, não é [ele] que transforma a maneira de pensar, de falar e de agir; ele apenas cria as condições para sua eventual transformação pelos próprios alunos" (SCHNEUWLY, 200gb, p. 33). Tais posicionamentos nos remetem à importância da formação do professor e dos 'saberes de referência' (VANHULLE, 200gb; HOFSTETTER e SCHNEUWLY, 2009) relativos ao ensino e à prática de sala de aula. Diante de tais considerações, abordaremos os aspectos que caracterizam a escrita e os meios que potencializam a sua aprendizagem e o desenvolvimento do sujeito escritor.

\section{Desenvolvimento da capacidade de produção escrita}

O ensino e aprendizagem da produção escrita ocupa um importante espaço nas pesquisas tanto a nível nacional quanto internacional, dada a dificuldade dos aprendizes relatada nas línguas primeira e estrangeira, constatação essa que se aplica ao ensino Fundamental, Médio e Superior (cf. Dolz et al., 2010; Schneuwly, 2008; Assis, 2014, 2015; Pereira e Graça, 2015; Parahyba e Leurquin, 2015; Boch e Grossman, 2015).

Em primeiro lugar, a referida dificuldade se deve à complexidade atribuída à escrita, conforme explica Vygotski (2009, p. 314):

"a linguagem escrita é a álgebra da escrita [...], de igual maneira a álgebra da escrita ou linguagem escrita introduz a criança no plano abstrato mais elevado da linguagem, reconstruindo, assim, o sistema psicológico da linguagem falada anteriormente constituído"

Segundo Schneuwly (1995, p. 83), Vygotski apresenta uma nova dimensão do funcionamento da linguagem sobre cujas ramificações pouco se sabe. Schneuwly acrescenta que o autor russo foi inovador na sua interpretação da linguagem e da escrita. Segundo ele, essa concepção é revolucionária, pelo fato de ser "radicalmente nova" e pelo fato de conceber "o desenvolvimento como sendo submetido a mudanças radicais, como construção de formas totalmente novas do funcionamento 
psíquico". Contudo, como explica Schneuwly, essa concepção traz consigo um questionamento: Trata-se "de saber como essa transformação é possível". Acrescentamos outros questionamentos: a dificuldade de escrever reside apenas no sujeito escritor? Ou estaria ela também relacionada com a capacidade do professor de ensinar a produção escrita? O ensino e a educação são fundamentais nesse processo, mas é necessário também apreender os processos de internalização e de apropriação das ferramentas que levam ao desenvolvimento da capacidade de escrever.

Em segundo lugar, a dificuldade na produção escrita decorre, a nosso ver, de uma formação docente que não contempla os "saberes de referência e práticos" (VANHULLE, 2009b; HOFSTETTER e SCHNEUWLY, 2009) relativos ao ensino e aprendizagem da produção escrita. Pode-se qualificar de formação 'insuficiente' ou 'inexistente' conforme evidenciado por Parahyba (2011) e Parahyba e Leurquin (2015). Tais fatores contribuem para a falta da internalização e apropriação das ferramentas propiciadoras de desenvolvimento da capacidade de produção escrita na língua inglesa. Paralelamente, as representações atinentes à escrita concorrem para um 'ciclo sem saída'. Esses últimos pontos serão discutidos em seção posterior.

Ao explicar em que consiste aprender a escrever, Schneuwly (1995, p. 83) afirma que se trata de "entrar na ordem da escrita por meio da apropriação de ferramentas construídas para nela agir, a saber, os gêneros". Assim, quando o aluno se apropria do gênero, ocorre a transformação do funcionamento da linguagem ou das capacidades de linguagem. Mediante o gênero como ferramenta ou objeto de ensino, o sujeito escritor desenvolve sua capacidade de escrever um texto atendendo às características específicas de uma determinada situação de comunicação (DOLZ e TUPIN, 2011).

Como mostra Schneuwly (1988, p. 50-51), ao aprender a linguagem escrita, o aluno constrói uma nova função de linguagem. Ademais, a aprendizagem de produção de textos escritos leva sempre à aprendizagem de um agir de linguagem em situações novas. Do ponto de vista psicológico, há dois processos que precisam ser acionados e dominados. O primeiro envolve a planificação do texto, que deve ocorrer ao longo de sua produção. O segundo implica a ação de estabelecer uma relação mediatizada com a situação material de produção. Em nível psicológico, trata-se de um funcionamento que requer gestão e controle que caracterizam a produção escrita. 
Ou seja, a escrita permite que o sujeito escritor faça uma autogestão do sistema de produção de linguagem em geral. Schneuwly conjectura que a produção escrita pressupõe a transformação de um sistema de linguagem anteriormente constituído, nesse caso, a linguagem oral, que se dá através de operações pelas quais o indivíduo vai diversificar e tornar mais complexas as operações de linguagem.

Ademais, como explica Schneuwly (1985, p.187-188), além da capacidade de planificação e do distanciamento da relação do locutor com seu enunciado que a produção escrita requer, a capacidade de reflexão consciente sobre a língua e a linguagem deve ser desenvolvida. Desse modo, vários aspectos dos textos escritos, tais como a relação entre texto e contexto, enunciador e seu texto, a estrutura do texto e a relação entre as partes do texto escrito, requerem uma 'representação precisa e consciente'. Assim, o sujeito escritor poderia e deveria ter controle sobre tais aspectos, ou seja, o sujeito deve desenvolver o controle sobre seu comportamento de produção de linguagem ou seu agir de linguagem. Em suma, "as possibilidades autorreflexivas da linguagem constituem mediadores influentes do comportamento linguageiro na aquisição da escrita" (SCHNEUWLY, 1985, p. 201).

Coadunamos com o pensamento de Dolz et al. (2010) quando eles defendem, que "não se aprende a escrita em geral, mas em função dos textos a serem produzidos e das situações de comunicação em que são postos em funcionamento" (2010, p. 18). Para isso, faz-se necessário abordar a escrita como objeto de ensino e de aprendizagem, focando os gêneros a serem trabalhados e produzidos. Paralelamente, na opinião de Schneuwly (2008, p. 120), desenvolve-se o domínio da produção escrita não apenas através do domínio do gênero, mas também através de um vocabulário específico ou de uma linguagem acerca do gênero, que auxiliam e orientam a produção escrita.

Para esse fim, a "didática da escrita", fruto das pesquisas nos campos da engenharia didática e da didática das línguas (BRONCKART et al, 1985), se apresenta como meio para ensinar a escrita e potencializar o desenvolvimento da capacidade do aluno a produzir gêneros escritos variados. A didática da escrita permitiu definir os objetos de ensino relativos à produção escrita. Nas palavras de Dolz e Tupin (2011, p. 90), foi desenvolvida " uma abordagem da produção escrita através do prisma do gênero textual como unidade organizadora de seu ensino". Segundo os autores, para 
que haja apropriação e internalização, é imprescindível que o aprendiz seja confrontado com os gêneros textuais e possa reconhecer suas características, bem como os valores atribuídos em função das condições de sua utilização. A partir dessa compreensão do ensino e aprendizagem da escrita, foi concebido o referencial metodológico: as sequências didáticas (DOLZ e SCHNEUWLY, 1998; DOLZ, NOVERRAZ e SCHNEUWLY, 2001; SCHNEUWLY e DOLZ, 2004). Trata-se de um procedimento centrado na "didatização do gênero" e na "elementarização" (CORDEIRO e SCHNEUWLY, 2007) que visa à decomposição dos diferentes componentes do gênero, que serão objeto de ensino.

Em resumo, as pesquisas elencadas evidenciam os caminhos que levam a um ensino potencializador de desenvolvimento e de transformação nas capacidades de linguagem dos aprendizes de produção escrita. Isso nos conduz a salientar que a didática das línguas e a didática da escrita pressupõe uma formação que abrange os 'saberes a ensinar' e os instrumentos necessários para sua efetivação. Acrescentaremos outro fator: a mudança de atitude do professor em relação à escrita.

\section{Sobre o trabalho do professor: algumas condições}

\section{Formação e saber}

Nos últimos dez anos, o trabalho do professor tornou-se um objeto de pesquisa privilegiado no campo das pesquisas sobre a educação (SCHNEUWLY, 200gb). No Brasil, há um número expressivo de pesquisas acerca da formação do professor (MACHADO, 2007; KLEIMAN, 2008; MACHADO e CRISTOVÃO, 2009), que analisam a questão da formação sob várias perspectivas na tentativa de encontrar respostas para entender o trabalho do professor ou de propor formas de desenvolvimento profissional.

Uma das facetas da análise do trabalho do professor implica a análise de suas capacidades. Segundo Bronckart (2008, p. 102, grifo original),

Interessar-se pelos processos desenvolvidos pelos alunos continua sendo indispensável, mas também é necessário compreender quais são as capacidades requeridas dos professores, para que eles possam ser bem-sucedidos no que é específico de sua profissão: a gestão de uma situação de sala de aula e do desenvolvimento de cada aula, em função das expectativas e dos objetivos predefinidos pela instituição escolar e das características e das reações efetivas dos alunos. 
Bronckart (2006) explica também que o ponto central da questão não é o conhecimento pleno da matéria que vai ensinar, nem o conhecimento da capacidade cognitiva do aluno. Segundo esse autor, a 'profissionalidade do professor' constitui-se pela "capacidade de pilotar um projeto de ensino predeterminado, negociando permanentemente com as reações, os interesses e as motivações dos alunos" (BRONCKART, op. cit., p. 226). Ao mesmo tempo, a 'profissionalidade' implica que o professor deve proceder na sua classe levando em conta vários aspectos, entre eles os que se relacionam com o lado sociológico, o material, o afetivo, o disciplinar (BRONCKART, 2006). Podemos depreender que há várias dimensões implicadas na construção dessas capacidades. Isso nos remete à questão da formação do professor e dos aspectos ligados à qualificação profissional. Essa disciplina, que provocou o avanço de instituições de ensino e de formação, resultou no fato de que um número cada vez maior de pessoas tem como missão formar outras. Assim, tanto os professores quanto os formadores estão reunidos em torno do mesmo objetivo ou função: a de formar outras pessoas (HOFSTETTER e SCHNEUWLY, 2009). Essa formação consiste em ensinar saberes a outrem. Esses autores mostram que há dois saberes aos quais se referem as 'profissões do ensino e da formação': "os saberes a ensinar ${ }^{5}$, ou seja, os saberes que são os objetos de seu trabalho; e os saberes para ensinar, ou os saberes que são as ferramentas de seu trabalho" (HOFSTETTER e SCHNEUWLY, op. cit., p. 17-18).

A atividade de formar, com a multiplicidade de ações que ela requer, é resumida da seguinte maneira:

Formar, como toda atividade humana, implica dispor de saberes para efetivá-la, que constituem as ferramentas de trabalho, neste caso, saberes para formar ou saberes para ensinar [...]. Trata-se notadamente de saberes sobre 'o objeto' de trabalho de ensino e de formação (sobre os saberes a ensinar e sobre o aluno, o adulto, seus conhecimentos, seu desenvolvimento, as maneiras de aprender, etc.), sobre as práticas de ensino (métodos, procedimentos, dispositivos, recortes dos saberes a ensinar, modalidades de organização e de gestão) e sobre a instituição que define seu campo de atividade profissional (planos de estudo, instruções, finalidades, estruturas administrativas e políticas, etc.) Como acontece para toda profissão, esses saberes são multiformes (HOFSTETTER e SCHNEUWLY, 2009, p.19. Grifo no original).

\footnotetext{
${ }^{5}$ Grifo nosso.
} 
Diante dessa diversidade de aspectos ligados aos saberes necessários para o trabalho de formação e a profissionalidade do professor, como se dá a apropriação dos saberes? Vanhulle (2009b, p. 168) é categórica quando afirma que "os saberes profissionais não se adquirem, se constroem". Ao citar Tardif, Lessard e Lahaye, (1991), Vanhulle reconhece que, de fato, a formação dos futuros professores oferece referenciais variados que vão thes servir de base para adquirir ou consolidar saberes e competências, academicamente e socialmente definidos como elementos que constituem a profissão. No entanto, como mostra a autora, para que esses referenciais se transformem em saberes profissionais reais, eles precisam ser reelaborados semioticamente pelos alunos em formação. Isso vai depender do quão significativos são os elos quando o aluno tenta trabalhar com suas experiências nos meios de formação, por meio da prática.

Considerando que os saberes profissionais, adquiridos com base nos referenciais acadêmicos e institucionais, constroem-se em ligação com o trabalho e através da prática - que, por sua vez, vão propiciar outros saberes - estamos diante de saberes distintos. Para Vanhulle (200gb, p. 170), são dois tipos: os 'saberes de referência', com base em Hofstetter e Schneuwly (2009) e os 'saberes práticos'. Compreender essa distinção implica falar na transformação desses saberes, ou seja, nos processos necessários para a mobilização desses saberes de referência com vistas a transformá-los em saberes práticos. Para que isso se efetive, ocorre um processo de didatização dos objetos de ensino (DOLZ e PLANE, 2008) para que sejam, segundo Machado e Cristovão (2009, p. 129), "efetivamente ensinados de acordo com o nível das capacidades dos alunos, isto é, [que se efetive] uma transposição didática".

\section{Gesto didático e ferramentas de ensino}

Outro conceito atrelado ao trabalho do professor é o 'gesto didático' que permite a observação da maneira como o professor faz uso das 'ferramentas de ensino' na construção do objeto de ensino. Essas ferramentas não são materiais, na medida em que o trabalho do professor tem como objeto os processos psíquicos dos aprendizes (SCHNEUWLY, 2008). Com base em sua concepção de educação e desenvolvimento, Vygotski (1985, p. 39) afirma que "os instrumentos psicológicos são 
elaborações artificiais; são sociais por natureza e não orgânicos ou individuais; são destinados ao controle dos processos do próprio comportamento ou dos outros". Portanto, o professor trabalha sobre as maneiras de pensar, de falar e de agir do aluno por meio de ferramentas semióticas. Segundo Schneuwly (2008, p. 59), o ensino ou 'trabalho de ensinar' é um trabalho que tem a mesma estrutura do que qualquer outro. Seu objetivo consiste em trabalhar sobre os modos de pensar, de falar e de agir. A ferramenta que usa são os signos ou os sistemas semióticos. Seu produto são os modos transformados. Em suma, o trabalho do professor consiste em transformar esses modos em função dos objetivos definidos pelo sistema escolar (SCHNEUWLY, 200gb). Dessa maneira,

O professor na qualidade de trabalhador é um agente de transformações [que produz], por meio das ferramentas semióticas uma série particularmente complexa de funções psíquicas como a escrita e a leitura, atividades linguageiras altamente desenvolvidas; ou como os modos de pensar disciplinares se manifestando, por exemplo, nos conceitos científicos, ou ainda como formas elaboradas de expressões artísticas ou artesanais (SCHNEUWLY, 2009b, p. 31).

O trabalho de ensino, que tem como objetivo a transformação, é ancorado em um processo de 'semiotização dupla'. Esse processo se define da seguinte maneira: um objeto de ensino é sempre, e necessariamente, desdobrado na situação de ensino. O objeto se torna presente por meio de procedimentos de ensino variados, materializando-se de diversas formas como objeto a ser aprendido e 'semiotizado', sobre o qual os alunos podem produzir novos significados. Também é objeto sobre o qual o professor guia a atenção do aprendiz por meio de procedimentos semióticos e mostra as dimensões essenciais, tornando-o objeto de estudo. (SCHNEUWLY, 2008, 200gb). Esse processo de 'guiar' constitui o ensino ou 'ação de ensinar', cujo significado etimológico é "fazer conhecer por meio dos signos" (REY, 1992, apud SCHNEUWLY, 200gb, p. 32). Portanto, "trata-se, fundamentalmente, de [objetos] que asseguram o encontro do aluno com o objeto e daqueles que asseguram o guiar da atenção" (SCHNEUWLY, 2008, p. 60).

\section{As representações no agir do professor}


O objetivo de abordar as representações neste artigo consiste em apreender as relações que o professor mantém com o objeto de ensino ou ensinado - a produção escrita em L2 com base nos gêneros textuais -, na medida em que podem influenciar e determinar o agir do docente e, consequentemente, o agir discursivo do aluno (PERRENOUD AEBI, 1997). No caso do presente trabalho, buscamos refletir sobre dois níveis de representação: a representação e a relação que o professor e o aluno mantêm com a língua estrangeira (DOLZ e WHARTON, 2008) e as representações relativas à produção escrita de ambos.

Falar de representações implica entrar nos mundos social, cultural e subjetivo do indivíduo - do professor e do aluno. Ancorada na teoria de Vygotski, Vanhulle (2009a, p. 243) explica a 'concepção cultural do sujeito'. Segundo essa concepção, "o indivíduo se desenvolve em uma cultura; é profundamente impregnado pelos artefatos através dos quais seus educadores e a sociedade o ensinaram a falar, a pensar e a agir". O interesse nas representações sociais pelos pesquisadores no campo das didáticas surgiu em função da necessidade de prover melhores condições de aprendizagem. Para isso, é necessário considerar as representações ou as concepções do aluno em relação a um objeto de ensino, haja vista que ele pode ter determinadas concepções enraizadas em seu pensamento em função de concepções ou hábitos adquiridos na sociedade ou na escola, ou até mesmo de imagens negativas acerca de algum objeto de ensino ou objeto ensinado.

No seu estudo sobre a formação de futuros professores, Vanhulle fala da ocorrência de processos de 'subjetivação' - les savoirs en "je". Tais processos dizem respeito às formas que os alunos dão aos saberes. Trata-se de uma "co-construção dos saberes e de si mesmo como sujeito social" (VANHULLE, 2009a, p. 69). Considerando que a subjetivação está relacionada com as formas que os indivíduos dão ao conhecimento, podemos inferir que cada indivíduo interpreta e se apropria do saber à sua maneira. Por conseguinte, o saber será revestido e impregnado de subjetividade, ou seja, será 'subjetivado' no momento em que for usado pelo (futuro) professor. A percepção de tal fenômeno não é algo evidente. A conscientização do sujeito pode ocorrer mediante o processo de autorreflexão sobre o uso dos saberes na prática. 
Sabe-se que as identidades não podem ser formatadas através da formação, como mostra Vanhulle (2009a). Sendo assim, como indaga a autora, seria possível formatar os papéis sociais? Na pesquisa que fez com os alunos em formação docente, a autora viu que, no geral, os alunos se apropriam das práticas didáticas inovadoras. No entanto, os resultados das análises dos diários reflexivos apresentados por Vanhulle sugerem um caminho distinto.

As representações acerca da produção escrita entre os adultos, tanto em nível do usuário da escrita quanto em nível do professor que ensina a produção escrita foram tema de pesquisas (PERRENOUD AEBI, 1997). Foi demonstrado que o discurso e as representações relativas à escrita influenciam as próprias práticas de produção escrita (PERRENOUD AEBI, op.cit.; SCHNEUWLY, 2008). O último autor explica que "se constrói uma relação com a escrita que é uma parte essencial da capacidade de escrever. Essas práticas são construções sociais, e ainda mais socialmente diferenciadas" (SCHNEUWLY, op.cit., p. 120).

Quando Perrenoud Aebi (1997, op. cit., p. 35) coloca como condição que "para poder escrever, é necessário ter sido instruído sobre a escrita", a autora mostra, ao mesmo tempo, a necessidade do ensino para a aprendizagem da produção escrita e o peso do imaginário das pessoas em geral, para quem a escrita é uma capacidade nata, que dispensa, portanto, o ensino. Estabelecer o ensino da escrita como necessidade é inquestionável. Contudo, como lidar com as representações dos professores? E até que ponto elas influenciam tanto o agir do professor quanto o desenvolvimento dos alunos? No seu estudo, Perrenoud Aebi vê a importância de se ter um melhor conhecimento das representações dos professores acerca da produção escrita e de seu ensino no âmbito da formação docente. A influência das representações é evidente no trabalho da pesquisadora. Os resultados de sua pesquisa são surpreendentes, como mostra a autora:

Quando examinamos as representações dos professores, ficamos surpresos pela sua homogeneidade por um lado, e pela interdependência que existe entre a maneira como os professores concebem a escrita e seu ensino e sua própria experiência acerca dessa prática, por outro lado. Se todos os professores se mostram muito críticos em relação ao ensino que receberam na sua infância [...], eles se mostram bastante desarmados quando se trata de descrever as ferramentas que precisariam colocar à disposição de seus alunos para ensiná-los a escrever. Sem dúvida, em parte, 
podem-se atribuir as respostas dos professores à ausência de uma formação nessa área (PERRENOUD AEBI, 1997, p. 162-163).

A influência das representações no agir do professor, demonstrada pela autora, revela o quanto essa dimensão continua atual nas discussões e pesquisas sobre a didática da escrita. Em um estudo sobre as pesquisas relativas à escrita nos países francófonos, Bronckart (2015, p.36) mostra que os resultados levam a considerar que "um ensino eficaz da escrita devia incluir, necessariamente, um trabalho de transformação das atitudes e das representações relativas ao estatuto e às condições da atividade da escrita".

\section{Conclusão}

Ao final dessa discussão teórica e reflexão sobre a didática da escrita e dos diferentes fatores que contribuem para o desenvolvimento e a transformação da capacidade de escrever na língua estrangeira, podemos elencar a relevância: (a) do papel do ensino e do professor no desenvolvimento do aprendiz da produção escrita, tendo em vista que se trata de uma atividade de linguagem altamente desenvolvida; (b) da apropriação dos saberes pelo professor no que se refere às ferramentas de ensino, aos objetos de ensino e sua efetiva transposição didática; (c) dos gestos didáticos e da interação professor-aluno que favorecem o desenvolvimento e (d) do entendimento das reais necessidades dos alunos. Esses argumentos nos remetem à formação do professor, que seria considerada eficaz se fosse desenvolvida nele a capacidade de transformar os saberes de referência em objetos de ensino para tornalos objetos efetivamente ensinados. Não menos importante é nosso argumento de que o ensino da produção escrita deve ser sistemático tendo o gênero textual como instrumento ou objeto de ensino.

\section{Referências bibliográficas}

ASSIS, J. A. Ações do professor e do universitário nas práticas de ensino e de aprendizagem da escrita acadêmica: o papel da avaliação e da reescrita no processo de apropriação do gênero resenha. Eutomia, vol. 2, nº 14, Recife: Universidade Federal de Pernambuco, 2014.

<http://www.repositorios.ufpe.br/revistas/index.php/EUTOMIA/issue/view/34/sho> 
. "Eu sei mas não consigo colocar no papel aquilo que eu sei" Representaçãoes sobre os textos acadêmico-científicos. In: RINCK, F.; BOCH, F.; ASSIS, J. A. (Org.) Letramento e Formação universitária: formar para a escrita e pela escrita. Campinas: Mercado de letras, 2015, p.423-454.

BOCH, F.; GROSSMAN, F. Sobre o uso de citações no discurso teórico: de constatações a proposições didáticas. In: RINCK, F.; BOCH, F.; ASSIS, J. A. (Org.) Letramento e Formação universitária: formar para a escrita e pela escrita. Campinas: Mercado de letras, 2015, p.283-307.

BRONCKART, J-P. Um retorno necessário à questão do desenvolvimento. In: BUENO, L.; LOPES, M. A. P. T.; CRISTOVÃO, V. L. L (Org.) Gêneros textuais e formação inicial. Campinas: mercado de Letras, 2013, p.85-107.

- Meio século de didática da escrita nos países francófonos: balanço e perspectivas. In:

RINCK, F.; BOCH, F.; ASSIS, J. A. (Org.) Letramento e formação universitária: formar para a escrita e pela escrita. Campinas: Mercado de Letras, 2015, p. 27-56.

O agir nos discursos: das concepções teóricas às concepções dos trabalhadores. Campinas: Mercado de Letras, 2008.

Atividade de linguagem, discurso e desenvolvimento humano. MACHADO; MATÉNCIO (Org.). Campinas: Mercado de Letras, 2006.

BRONCKART, J. P. et al. Le fonctionnement des discours: un modèle psychologique et une méthode d'analyse. Lausanne: Delachaux e Niestlé, 1985.

CORDEIRO e SCHNEUWLY, CORDEIRO, G. S.; SCHNEUWLY, B. La construction de l'objet enseigné et les organisateurs du travail enseignant. In : Recherche et Formation, $\mathrm{N}^{\circ} 56,2007$.

http://ife.ens-lyon.fr/publications/edition-electronique/recherche-et-

formation/RRo56-05.pdf Acesso em 3 de junho de 2017.

DOLZ, J.; PLANE, S. Formation des enseignants et enseignement de la lecture et de l'écriture: recherches surles pratiques. Namur, France: Presses universitaires de Namur, 2008.

DOLZ, J.; GAGNON, R.; DECÂNDIO, F. Produção escrita e dificuldades de aprendizagem. Tradução Fábricio Decândio, Anna Raquel Machado. São Paulo: Mercado de Letras, 2010.

DOLZ, J.; NOVERRAZ, M.; SCHNEUWLY, B. Sequências didáticas para o oral e a escrita: apresentação de um procedimento. In: SCHNEUWLY, B.; DOLZ, J. Tradução R. Rojo, S. C. Cordeiro. Campinas: Mercado de Letras, 2004. 
DOLZ, J.; SCHNEUWLY, B. Apprendre à écrire ou comment étudier la construction de capacités langagières: études de linguistique appliquée-ELA 101. Paris: Didier Érudition, 1996a. p 73-86.

Genres et progression en expression orale et écrite: éléments de reflexions à propos d'une experience romande. Enjeux, n. 37-38. p. 49-74, 1996b.

Pour un enseignement de l'oral: initiation aux genres formels à l'école. Paris: ESF, 1998. p. 49-73.

DOLZ, J.; TUPIN, F. La notion de situation dans l'étude des phénomènes d'enseignement et d'apprentissage des langues : vers une perspective socio-didactique. Recherches en éducation, no. 12, 2011, p. 82-97.

DOLZ, J.; WHARTON, S. Une approche sócio-didactique comparée de l'enseignement des langues: le rôle des langues premières de socialisation. In: HANHART, S. et al. (Ed.). De la comparaison en éducation. Paris: L'Harmattan, 2008. p. 282-305.

FRIEDRICH, J. Lev Vygotski: médiation, apprentissage et développement: une lecture philosophique et épistémologique. Carnets des Sciences de l'Éducation. Genève: Université de Genève, 2010.

HOFSTETTER, R.; SCHNEUWLY, B. (Ed.). Savoirs en transformation: au coeur des professions de l'enseignement et de la formation. Bruxelles: De Boeck, 2009.

KLEIMAN, A. B. As metáforas na educação linguística do professor: índices da transformação de saberes na interação. In: KLEIMAN, A. B.; MATENCIO, N. L. M. (Org.) Letramento e formação do professor: práticas discursivas, representações e formação do professor. São Paulo: Mercado de Letras, 2008, p. 203-228.

MACHADO, A. R. Por uma concepção ampliada do trabalho do professor. In: GUIMARÃES, A., M. M.; MACHADO. A. R. E COUTINHO, A (Org.) O interacionismo sociodiscursivo: questões epistemológicas e metodológicas. Campinas: Mercado de Letras, 2007, p. 77-97.

MACHADO, A. R.; CRISTOVÃO, V. L. L. Representações sobre o professor e seu trabalho em proposta institucional brasileira para a formação docente. In: ABREUTARDELLI e CRISTOVÃO (Orgs). Linguagem e educação: o trabalho do professor em uma nova perspectiva. Campinas: Mercado de Letras. 2009, p. 117-136.

PARAHYBA, F. D. Avaliação e reescrita: desenvolvimento das capacidades de produção textual em inglês. Tese de doutorado. Universidade Federal da Paraíba, 2011

file:///C:/Users/Fatiha/Downloads/TESE_FATIHA_DECHICHA_PARAHYBA.pdf 
PARAHYBA, F. D. ; LEUROUIN, E.. Um retrato da formação inicial de professores de línguas: duas cenas. Revista Eutomia, v. 1., n. 15. Dezembro, Recife, Universidade Federal de Pernambuco, 2015, p.288-314.

https://periodicos.ufpe.br/revistas/EUTOMIA/article/view/1657/1267,

PEREIRA, L. A; GRAÇA, L. Formação dos Professores para o ensino da produção de textos escritos: possiveis e impossíveis. In: LEUROUIN, $E_{i}$ COUTINHO, M. A.; MIRANDA, F (Org.) Formação docente: textos, teorias e práticas. Campinas: Mercado de Letras, 2015, p. 55-74.

PERRENOUD AEBI, C. Enseigner l'écriture: paroles d'enseignants. Cahiers des Sciences de l'Éducation, 84. Genève: Université de Genève, 1997.

SCHNEUWLY, B. Apprendre à écrire: une approche socio-historique. In: BOYER, J.Y. DIONNE, J. P; RAYMOND, P. (Ed.). Vers un modèle de l'enseignement/apprentissage de l'écriture. Montréal: Logiques, 1995. p. 73-100.

La construction sociale du langage écrit chez l'enfant. In: SCHEUWLY, B.; BRONCKART, J. P. (Dir.). Vygotski aujourd'hui. Neuchâtel: Delachaux et Niestlé, 1985. p. 169-201.

Le langage écrit chez l'enfant: la production des textes informatifs et argumentatifs. Paris: Delachaux et Niestlé, 1988.

L'objet enseigné. In: SCHNEUWLY, B.; DOLZ, J. Des objets enseignés en classe de français. Rennes: Presses Universitaires de Rennes, 2009a. p.17-28.

Le travail enseignant. In: SCHNEUWLY, B.; DOLZ, J. Des objets enseignés en classe de français. Rennes: Presses Universitaires de Rennes, 200gb. p. 29-43.

Vygotski, l'école et l'écriture. Cahier, 118. Genève: Université de Genève, 2008.

SCHNEUWLY, B.; BRONCKART, J. P. (Dir.). Vygotski aujourd'hui. Neuchâtel: Delachaux et Niestlé, 1985.

SCHNEUWLY, B.; DOLZ, J. Des objets enseignés en classe de français. Rennes: Presses Universitaires de Rennes, 2009.

Gêneros orais e escritos na escola. Tradução R. Rojo, S. G. Cordeiro. Campinas: Mercado de Letras, 2004.

Les genres scolaires: des pratiques langagières aux objets d'enseignement. Repères, n. 15, p. 27-40, 1997.

VANHULLE, S. Des savoirs em jeu aux savoirs em "je": cheminements réfléxifs et subjectivation des savoirs chez des jeunes enseignants em formation. Berne: Peter Lang, 2009a. 
Savoirs professionnels et construction sociodiscursive de l'agir. VALS-ASLA: Bulletin Association Suisse de Linguistique Appliquée, n. 90, p.167-188, $2009 \mathrm{~b}$.

VYGOTSKI, L. S. A construção do pensamento e da linguagem. Tradução Paulo Bezerra. São Paulo: Martins Fontes, 2009.

Le problème de l'enseignement et du développement mental à l'âge scolaire. In: SCHNEUWLY, B.; BRONCKART, J. P. (Dir.). Vygotski aujourd'hui. Neuchâtel: Delachaux et Niestlé, 1985. p. 95-117.

i Fatiha Dechicha Parahyba, professora de língua inglesa do Departamento de Letras da UFPE. Atualmente em Estágio de Pós-Doutorado no Programa de Pós-graduação em Linguística da Universidade Federal do Ceará, como bolsista do PNPD/CAPES. É membro do Grupo de Estudos e Pesquisas em Linguística Aplicada (GEPLA)- UFC.

fatihadpb@gmail.com 